\title{
Sistem Pemesanan Makanan dan Minuman Pada Restoran Menggunakan Teknologi NFC Berbasis Android
}

\author{
Anissa Yolanda Putri, Dodon Yendri \\ Jurusan Sistem Komputer FTI Universitas Andalas Limau Manis Kota Padang 25163 INDONESIA
}

\section{ARTICLE INFORMATION}

Received: January 18,18

Revised: March 05, 18

Available online: March 29, 18

\section{KEYWORDS}

NFC, Smart phone, Raspberry pi,
Android
Android

\section{CORRESPONDENCE}

E-mail: dodon575@gmail.com

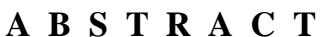

One area of business that is in great demand today is the culinary field. The culinary field is very mushrooming because it deals with meeting basic human needs. Therefore service to digital needs to be a concern. The goal is to improve services with NFC (Near Field Communication) based on Android for ordering food and drinks. This research uses experimental research methods by applying NFC that is on smart phones as a way to bring the smart phone closer to the NFC tag that is already on each table. Message data entered on a mini PC computer (Raspberry Pi) as the server for the next as a booking order that will be ordered by the waiter. Simulation show that a system can read NFC tags and find out table numbers via a smart phone with a $100 \%$ success rate, remote reading of NFC tags by smart phones is $2.5 \mathrm{~cm}$ and the average time by the system is 1,12 seconds. Besides that, the system is also equipped with calculations for payments with $100 \%$ accuracy.

\section{PENDAHULUAN}

Teknologi informasi dan komunikasi memberikan dampak yang cukup besar terhadap pola kehidupan manusia. Dengan hadirnya telepon pintar (smart phone) membuat manusia semakin dimanjakan dalam segala hal. Manusia tidak perlu bersusah-susah untuk mendapatkan sesuatu yang mereka inginkan, tidak terkecuali dalam bidang pelayanan. Manusia tidak keberatan membayar mahal asal mereka mendapatkan kepuasan dan kenyamanan dalam pelayanan.

Dewasa ini dengan hadirnya berbagai aplikasi, memberikan banyak pilihan dalam melakukan suatu aktifitas, baik melalui aplikasi yang bersifat dekstop based, web based hingga munculnya aplikasi-aplikasi baru yang dapat berjalan pada mobile dengan platform yang berbeda-beda. Android yang merupakan suatu sistem operasi yang menyediakan platform terbuka bagi para pengembang, menawarkan banyak kemampuan pengembangan untuk membangun aplikasi yang sangat kaya dan inovatif.

Dengan adanya android perkembangan teknologi saat sekarang ini semakin mengarah kepada sistem kontrol otomatis. Sistem kontrol otomatis merupakan suatu sistem yang digunakan untuk mengendalikan mesin-mesin industri dan kontrol proses untuk memudahkan pekerjaan manusia. Sistem kontrol otomatis tidak hanya dimanfaatkan dunia industri saat ini, melainkan juga sudah menyebar luas ke bidang-bidang lain seperti bidang kuliner[1].

Salah satu bentuk pemanfatan teknologi sistem kontrol otomatis yang dapat digunakan pada smart phone adalah untuk melakukan pemesanan menu pada restoran. Saat ini restoranrestoran di Indonesia masih banyak yang belum menerapkan sistem pelayanan otomatis seperti pada negara-negara maju. Dimana pekerjaan sehari-hari seperti melayani pelanggan, pemesanan.

Menu, pembayaran dan menjadi kasir masih dikerjakan oleh manusia [2]. Hal ini membuat pelayanan menjadi terlambat.

Bidang usaha kuliner merupakan salah satu bidang yang banyak diminati wira usahawan, karena selain sebagai pemenuhan kebutuhan pokok juga sangat menjanjikan dibandingkan dengan bidang-bidang usaha lain. Oleh karena itu pelayanan terhadap pelanggan harus menjadi perhatian yang serius.

Tujuan penelitian adalah merancang suatu aplikasi sistem untuk meningkatkan pelayanan dengan menerapkan teknologi NFC (Near Field Communication) yang ada pada samrtphone berbasis android dalam melayani pemesanan makanan dan minuman. Pemesanan dilakukan dengan cara mendekatkan smart 
phone android yang memiliki fitur NFC ke NFC tag yang sudah disiapkan pada masing-masing meja untuk mengidentifikasi pemesanan. Disamping itu aplikasi juga dilengkapi dengan informasi kandungan gizi kepada pelanggan yang disertakan dengan bahan-bahan, sehingga pelanggan yang tidak boleh mengkonsumsi bahan tertentu dapat menggantinya dengan menu lainnya.

\section{LANDASAN TEORI}

\section{Near Field Communication (NFC)}

NFC atau Near Field Communication diartikan sebagai suatu komunikasi medan dekat yang merupakan perangkat teknologi konektivitas nirkabel berbasis teknologi Radio Frecuency Identity (RFID). NFC secara otomatis langsung dapat mengkoneksikan kedua perangkat dengan cepat sesuai kebutuhan tanpa di set terlebih dahulu. Saat ini teknologi NFC sudah masuk kedalam banyak smart phone, seperti di Android : Nexus 4, Galaxy Nexus, Nexus S, Galaxy S III dan HTC One X. Di Windows Phone : Nokia Lumia Series, HTC Windows Phone 8X dan Blackberry.

NFC beroperasi pada frekuensi $13.65 \mathrm{MHz}$ dengan rata-rata kecepatan transfer 106-848 Kbps. NFC selalu melibatkan Frekuensi Radio (RF) yang dapat mengaktifkan target yang pasif. Hal ini memungkinkan target NFC untuk dapat mengidentifikasi device seperti tag, sticker, key fobs, ataupun kartu yang tidak memerlukan baterai[3].

Komunikasi NFC akan terjadi ketika dua perangkat yang mendukung NFC bertemu dan salah satunya menjadi inisiator atau sebagai target. Adapun maksimum jarak komunikasi antar perangkat yaitu $4 \mathrm{~cm}$, dengan pertukaran data sepersepuluh detik. Beberapa jenis koneksi perangkat NFC diantaranya adalah NFC smart phone/ponsel, kartu (tag) NFC dan NFC Reader seperti ditunjukkan pada gambar 1 berikut.

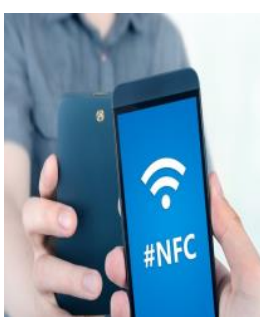

(a)

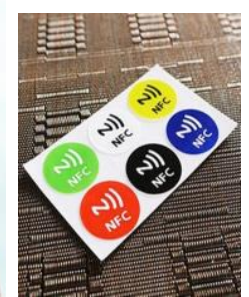

(b)

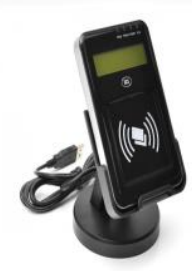

(c)

\section{Gambar 2.1 (a) NFC Ponsel, (b) NFC tag (Sticker) dan (c) NFC Reader}

Dari jenis koneksi di atas, teknologi NFC menawarkan tiga model operasi yakni read/write, peer-to-peer dan card emulation. NFC forum melakukan standarisasi terhadap seluruh lapisan (layers) mulai dari application level ke lapisan RF pada mode read/write dan peer-to-peer [4].

\section{Android}

Android adalah software untuk perangkat mobile yang meliputi sistem operasi, middle ware dan aplikasi inti. Android dilengkapi dengan Android
SDK (Software Development Kit) yang menyediakan tools dan mendukung kebutuhan Application Programming Interface (API) yang diperlukan untuk mengembangkan aplikasi pada platform android dengan menggunakan bahasa pemrograman Java.

Aplikasi android ditulis dalam bahasa pemrograman Java, yaitu kode Java yang terkompilasi bersama-sama dengan data dan file resources yang dibutuhkan oleh aplikasi yang digabungkan oleh Android Asset Packaging Tool (AAPT) menjadi paket Android, sebuah file yang ditandai dengan suffix.apk. File ini didistribusikan sebagai aplikasi dan dinstal pada perangkat mobile.

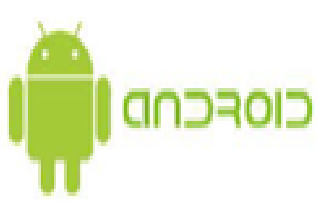

\section{Gambar 2.2 Logo Android}

Untuk menciptakan aplikasi mereka, para pengembang dapat memanfaatkan platform terbuka yang telah disediakan oleh android saat ini dengan berbagai macam piranti bergerak.

Pengembang dapat memiliki akses ke framework API yang sama dengan yang dapat diakses oleh aplikasi - aplikasi inti dari android dalam mengembangkan aplikasi [5].

\section{Raspberry Pi}

Raspberry Pi merupakan komputer kecil seukuran sebuah kartu kredit dengan berbagai fungsi yang dapat dilakukannya. Dikarenakan ukurannya yang jauh lebih kecil dari komputer biasa, kemampuan komputer mini inipun dibawah komputer biasa. Raspberry Pi kebanyakan digunakan untuk kegiatan pembelajaran yang tidak memerlukan alokasi memori yang begitu besar seperti belajar pemrograman.

Raspberry Pi dilengkapi dengan RAM berukuran 512MB. Dukungan lainnya adalah tersedianya USB, HDMI, dll. Media penyimpanan Raspberry Pi menggunakan SD-Card (Secure Digital Card) yang ditambahkan.

Raspberry Pi sudah meluncurkan versi barunya yaitu Raspberry Pi 3 Model B. Kelebihan Raspberry ini dari single board computer yang lain adalah sudah dilengkapi dengan Wi-Fi sehingga pengguna tidak perlu lagi menggunakan Wi-Fi dongle untuk terhubung ke jaringan internet[6]. Gambar 2 memperagakan sebuah Raspberry Pi 3 Model B. 


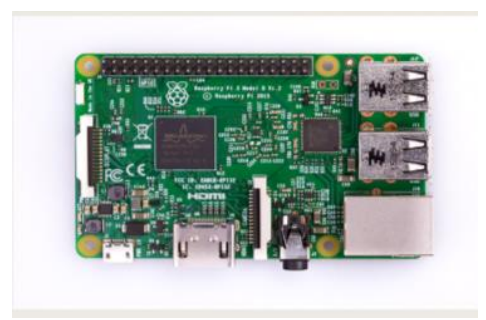

Gambar 2.3 Raspberry Pi 3 Model B

\section{Router}

Perangkat jaringan yang digunakan untuk menghubungkan beberapa jaringan baik jaringan yang sama maupun berbeda dari segi teknologinya disebut Router. Router merupakan sebuah alat yang dapat mengirimkan paket data ke sebuah jaringan atau internet menuju tujuannya melalui sebuah proses yang dikenal dengan routing.

Disamping itu untuk menghubungkan banyak jaringan kecil ke jaringan yang lebih besar yang dikenal dengan inter-network dapat digunakan router. Hal ini dapat meningkatkan kinerja jaringan dan mempermudah manajemen. Berikut adalah fungsi router diantaranya:

1. Menginterkoneksikan sejumlah jaringan untuk mengirimkan data dari suatu jaringan ke jaringan yang lain (fungsi utama).

2. Untuk mentransmisikan informasi dari satu jaringan ke jaringan lain dengan sistem kerjanya seperti Bridge[7].

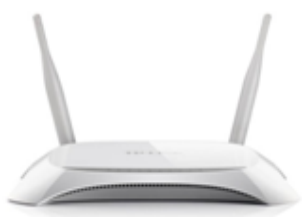

\section{Gambar 2.4 Router}

\section{METODE}

Metode penelitian yang digunakan pada penelitian ini adalah metode experimental research yang diawali dengan studi literatur. Studi literatur dilakukan untuk mempelajari karakteristik dari masing-masing komponen, dan kemudian dilanjutkan dengan analisis dan perancangan sistem. Analisis dilakukan untuk menentukan kebutuhan apa saja yang diperlukan dan bagaimana sistem dapat dilakukan. Perancangan sistem terdiri atas perancangan perangkat keras dan perancangan perangkat lunak.

Pada hasil perancangan dilakukan implementasi dan pengujian. Implementasi digunakan untuk melakukan pengkodean dan debugging yang kemudian diuji kebenarannya. Pengujian dilakukan untuk menguji apakah perangkat lunak dan perangkat dapat terintegrasi dengan baik sesuai dengan yang diharapkan. Berikut adalah langkah-langkah penelitian yang dilakukan seperti ditunjukkan pada gambar 2.5.

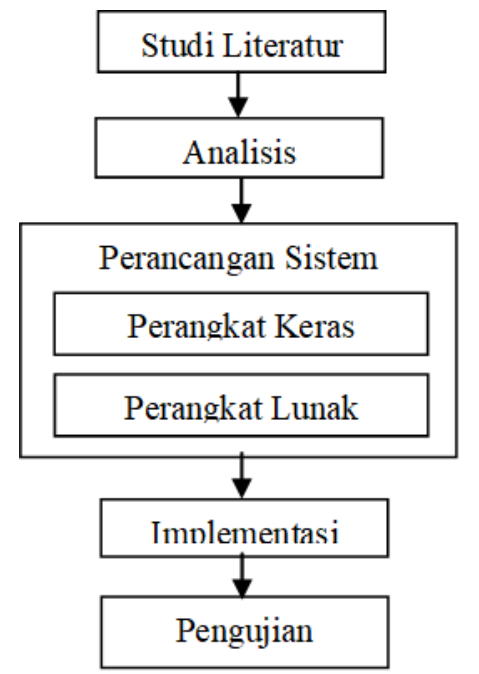

Gambar 2.5 Langkah-langkah penelitian

\section{Perancangan Sistem}

Perancangan sistem bertujuan untuk memberikan gambaran umum dengan jelas tentang sistem yang akan dibangun baik secara global maupun secara detil atau rinci. Perancangan sistem terdiri atas dua tahap yaitu perancangan keras dan perancangan perangkat lunak.

Perancangan perangkat keras dilakukan untuk merumuskan komponen-komponen perangkat keras yang akan digunakan yakni smart phone, router, monitor pc, raspberry pi, nfc tag, dan nfc reader. Secara umum blok diagram perancangan perangkat dapat dilihat pada gambar 2.6. Sedangkan perancangan perangkat lunak digunakan untuk membangun sebuah aplikasi android yang mengintegrasikan komponen perangkat keras yang digunakan sebagai input pemesanan makanan dan minuman kemudian datanya disimpan pada database.

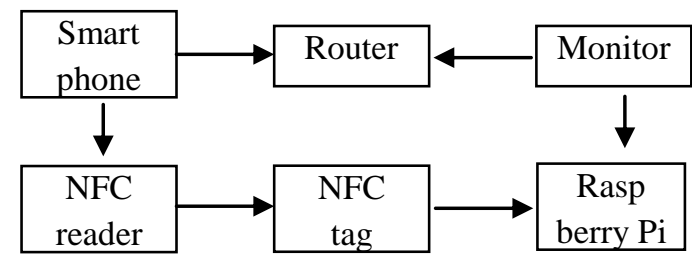

Gambar 2.6 Blok diagram sistem perangkat keras 
Dari gambar 2.6 diatas dapat dijelaskan bahwa untuk menghubungkan aplikasi pada smart phone dengan raspberry pi sebagai server digunakan router dengan wireless LAN-nya, sehingga data yang diterima dari smart phone dapat dikirim menuju server untuk dapat dilakukan pemrosesan pada database.

\section{HASIL DAN PEMBAHASAN}

Pelanggan yang datang ke restoran terlebih dahulu harus login pada aplikasi restoran sebelum memesan makanan dan minuman seperti terlihat pada gambar 4.1 berikut.

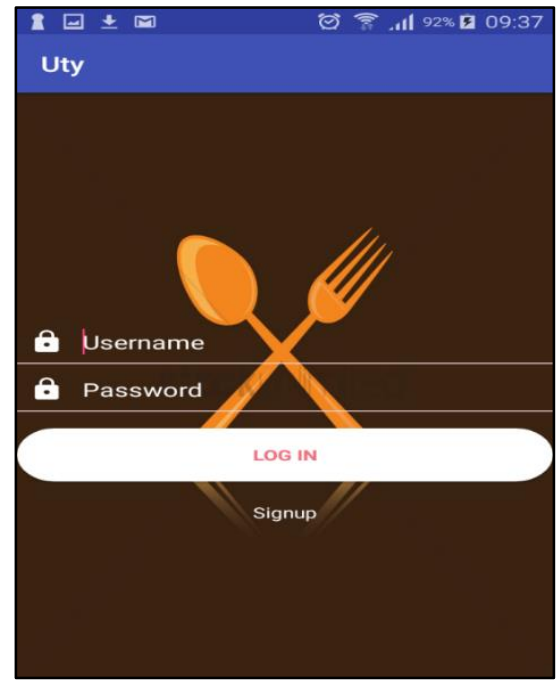

Gambar 4.1 Form log in sistem

Apabila user name dan password yang diinputkan sesuai dengan saat didaftarkan maka sistem akan membawa pelanggan ke pemilihan menu makanan dan minuman yang tersedia seperti terlihat pada gambar 4.2, tetapi jika tidak sesuai sistem akan menolak. Daftar menu ditampilkan berdasarkan kandungan gizi dan bahan-bahan pembuatnya, sehingga apabila pelanggan tidak boleh mengkonsumsi bahan tertentu dapat menggantinya dengan menu yang lain.

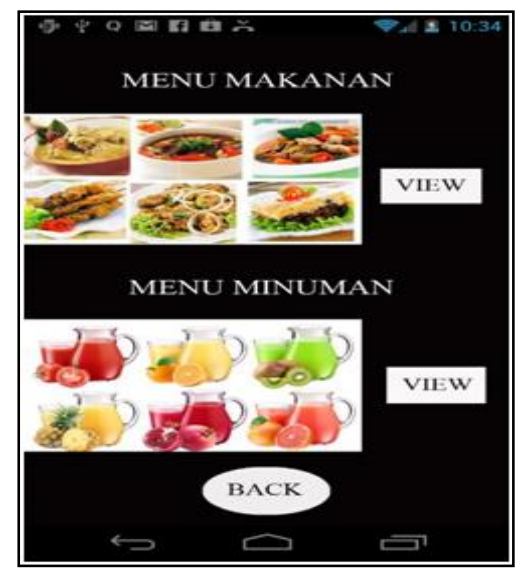

Gambar 4.2 Menu makanan dan minuman di restoran

\section{Pengujian NFC Tag}

Pengujian NFC tag dilakukan untuk melihat apakah tag bisa terdeteksi oleh smart phone dan sekaligus mengetahui nomor meja serta berapa jarak baca yang terdeteksi oleh smart phone terhadap NFC tag. Pengujian dilakukan dengan cara mendekatkan smart phone yang memiliki NFC (NFC reader) dengan NFC tag yang ada pada meja. Apabila UserID (UID) tag terdeteksi, maka suara pada smart phone akan berbunyi sebagai notifikasi. Hasil pengujian dapat dilihat pada gambar 4.3 beikut.

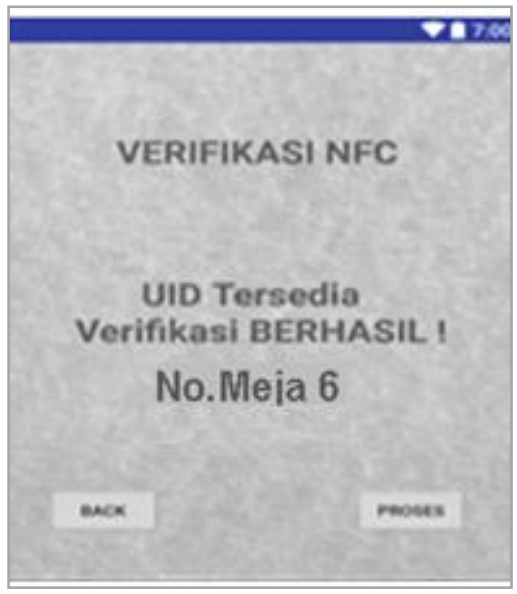

Gambar 4.3 Deteksi UID dan nomor meja

Dari enam kali pengujian yang dilakukan terhadap enam meja menggunakan smart phone Samsung Note 3 
SM-N750 dan NFC tag NTAG203 dengan jarak baca $0-2 \mathrm{~cm}$, maka diperoleh hasil seperti terlihat pada Tabel 4.1 berikut.

Tabel 4.1 Pengujian pembacaan NFC tag

\begin{tabular}{|c|c|c|c|}
\hline $\begin{array}{c}\text { Penguji } \\
\text { an ke }\end{array}$ & UID & No.Meja & Status \\
\hline 1 & $44 \mathrm{a} 99 \mathrm{e} 2 \mathrm{ec} 4 \mathrm{a} 81$ & 1 & Terdeteksi \\
\hline 2 & $471 \mathrm{~b} 1 \mathrm{e} 2 \mathrm{ec} 4 \mathrm{a} 80$ & 2 & Terdeteksi \\
\hline 3 & $4528 \mathrm{de} 2 \mathrm{ec} 4 \mathrm{a} 80$ & 3 & Terdeteksi \\
\hline 4 & $43 \mathrm{ac} 4 \mathrm{e} 2 \mathrm{ec} 4 \mathrm{a} 81$ & 4 & Terdeteksi \\
\hline 5 & $45 \mathrm{f} 8 \mathrm{ce} 2 \mathrm{ec} 4 \mathrm{a} 80$ & 5 & Terdeteksi \\
\hline 6 & $44 \mathrm{fbbe} 2 \mathrm{ec} 4 \mathrm{a} 80$ & 6 & Terdeteksi \\
\hline
\end{tabular}

Berdasarkan data pada Tabel 4.1 diatas, terlihat bahwa semua pengujian dapat mendeteksi semua UID pada enam meja, artinya sistem dapat mengenali NFC tag 100\%. Sedangkan pengujian jarak baca antara smart phone dan NFC tag terhadap dua jenis NFC tag pada jarak yang berbeda-beda seperti terlihat pada Tabel 4.2.

Tabel 4.2 Pengujian jarak pembacaan NFC tag

\begin{tabular}{|c|c|c|c|}
\hline $\begin{array}{c}\text { NFC } \\
\text { tag }\end{array}$ & UID & $\begin{array}{l}\text { Jarak } \\
(\mathrm{cm})\end{array}$ & $\begin{array}{c}\text { Terdeteksi/Tidak } \\
\text { terdeteksi }\end{array}$ \\
\hline \multirow{7}{*}{1} & $43 \mathrm{ac} 4 \mathrm{e} 2 \mathrm{ec} 4 \mathrm{a} 81$ & 0.0 & Terdeteksi \\
\hline & $43 \mathrm{ac} 4 \mathrm{e} 2 \mathrm{ec} 4 \mathrm{a} 81$ & 0.5 & Terdeteksi \\
\hline & 43ac4e2ec4a81 & 1.0 & Terdeteksi \\
\hline & $43 \mathrm{ac} 4 \mathrm{e} 2 \mathrm{ec} 4 \mathrm{a} 81$ & 1.5 & Terdeteksi \\
\hline & $43 \mathrm{ac} 4 \mathrm{e} 2 \mathrm{ec} 4 \mathrm{a} 81$ & 2.0 & Terdeteksi \\
\hline & $43 \mathrm{ac} 4 \mathrm{e} 2 \mathrm{ec} 4 \mathrm{a} 81$ & 2.5 & Tidak terdeteksi \\
\hline & 43ac4e2ec4a81 & 3.0 & Tidak terdeteksi \\
\hline \multirow{7}{*}{2} & $4528 \mathrm{de} 2 \mathrm{ec} 4 \mathrm{a} 80$ & 0.0 & Terdeteksi \\
\hline & 4528de2ec4a80 & 0.5 & Terdeteksi \\
\hline & $4528 \mathrm{de} 2 \mathrm{ec} 4 \mathrm{a} 80$ & 1.0 & Terdeteksi \\
\hline & $4528 \mathrm{de} 2 \mathrm{ec} 4 \mathrm{a} 80$ & 1.5 & Terdeteksi \\
\hline & $4528 \mathrm{de} 2 \mathrm{ec} 4 \mathrm{a} 80$ & 2.0 & Terdeteksi \\
\hline & $4528 \mathrm{de} 2 \mathrm{ec} 4 \mathrm{a} 80$ & 2.5 & Terdeteksi \\
\hline & 4528de2ec4a80 & 3.0 & Tidak terdeteksi \\
\hline
\end{tabular}

Dari pengujian yang dilakukan pada Tabel 4.2, jarak maksimal pembacaan NFC tag yang dapat terdeteksi oleh smart phone adalah $2.5 \mathrm{~cm}$.

Pengujian waktu respon pemesanan makanan dan minuman Setelah pemesanan makanan dan minuman selesai dilakukan seperti gambar 4.4, kemudian pelanggan mendekatkan smart phone dengan NFC tag yang sudah ada di meja restoran. Data
UID tag yang terbaca akan dikirim ke server melalui router dengan wireless LAN. Identifikasi dilakukan berdasarkan kecocokan UID tag dengan UID yang tersimpan pada database. Apabila UID tersedia maka pesanan segera akan diproses oleh pelayan sesuai dengan permintaan, namun jika tidak maka pesanan akan ditolak atau diabaikan.

Pengujian dilakukan oleh sistem dengan cara menghitung mulai dari pelanggan menekan tombol "Pesan" pada smart phone sampai sistem merespon pelanggan dengan menampilkan nomor meja pelanggan dan adanya notifikasi "pesanan anda sedang diproses, harap sabar menunggu" (lihat gambar 4.5)

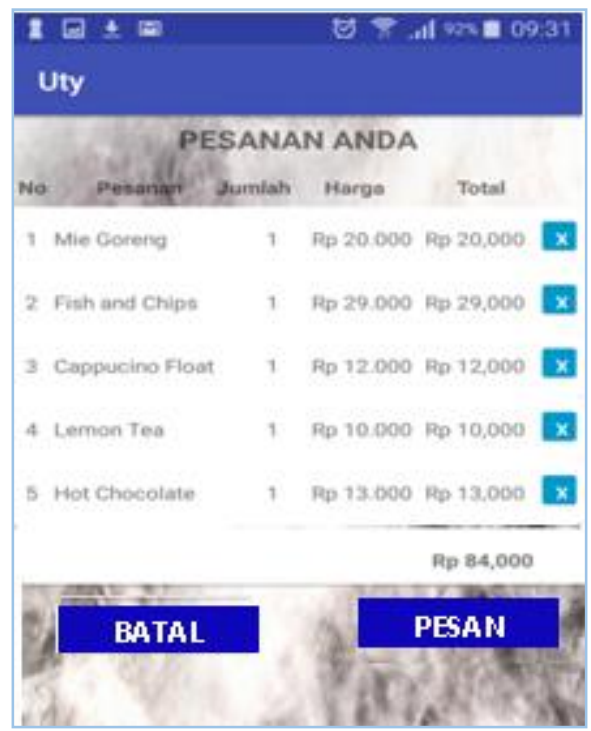

Gambar 4.4 Pemesanan menu

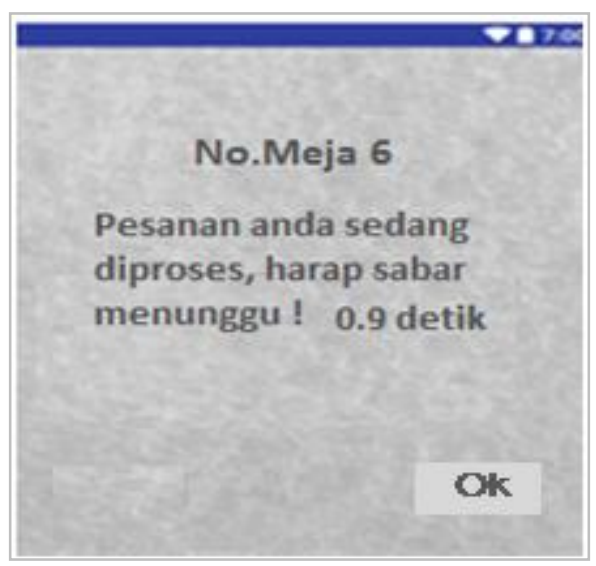

Gambar 4.5 Notifikasi dan respon sistem 
Hasil pengujian respon waktu oleh sistem ditunjukkan pada Tabel 4.3.

Tabel 4.3 Respon waktu pemesanan makanan dan minuman

\begin{tabular}{|c|c|c|}
\hline $\begin{array}{c}\text { Pengujian } \\
\text { ke }\end{array}$ & UID & $\begin{array}{c}\text { Waktu } \\
\text { (detik) }\end{array}$ \\
\hline 1 & $44 \mathrm{a} 99 \mathrm{e} 2 \mathrm{ec} 4 \mathrm{a} 81$ & 1.2 \\
\hline 2 & $45 \mathrm{f} 8 \mathrm{ce} 2 \mathrm{ec} 4 \mathrm{a} 80$ & 1.1 \\
\hline 3 & $44 \mathrm{fbbe} 2 \mathrm{ec} 4 \mathrm{a} 80$ & 1.3 \\
\hline 4 & $471 \mathrm{~b} 1 \mathrm{e} 2 \mathrm{ec} 4 \mathrm{a} 80$ & 0.9 \\
\hline 5 & $4528 \mathrm{de} 2 \mathrm{ec} 4 \mathrm{a} 80$ & 1.3 \\
\hline 6 & 43ac4e2ec4a81 & 0.9 \\
\hline \multicolumn{2}{|c|}{ Total waktu } & 6.7 \\
\hline
\end{tabular}

Berdasarkan pengujian pada Tabel 4.3 dapat dihitung rata-rata waktu yang diperlukan oleh sistem untuk merespon pemesanan menu oleh pelanggan adalah sebagai berikut:

$$
\begin{gathered}
\text { Waktu rata-rata }=\frac{\text { Total } \text { waktu }(\text { detik })}{\text { jumlah pengujian }} \\
=\frac{6.7}{6}=1.12 \text { detik }
\end{gathered}
$$

Jadi rata-rata respon waktu pemesanan yang diperlukan oleh sistem adalah sebesar 1.12 detik. Sedangkan lama waktu pesanan diantar ke meja pelanggan tergantung dari banyaknya makanan dan minuman yang dipesan oleh pelanggan. Semakin banyak menu yang dipesan, tentu semakin lama pesanan sampai pada meja pelanggan.

\section{Pengujian perhitungan tagihan atau bill}

Pengujian ini dilakukan untuk mengetahui tagihan atau bill pelanggan atas semua pesanan yang dilakukan. Perhitungan tagihan oleh sistem diproses secara otomatis pada saat pelanggan telah selesai memilih menu makanan atau minuman. Tabel 4.4 memperlihatkan hasil pengujian perhitungan tagihan oleh sistem aplikasi dibandingkan dengan perhitungan manual.
Tabel 4.4 Pengujian perhitungan tagihan pembayaran oleh sistem dibandingkan dengan manual

\begin{tabular}{|c|c|c|c|c|c|}
\hline \multirow{2}{*}{$\begin{array}{c}\text { N } \\
\text { o }\end{array}$} & UID & \multirow{2}{*}{ Meja } & \multicolumn{2}{|c|}{$\begin{array}{c}\text { Perhitungan } \\
\text { tagihan }(\mathrm{Rp})\end{array}$} & \multirow{2}{*}{ Ket } \\
\cline { 4 - 6 } & & & $\begin{array}{c}\text { pada } \\
\text { Sistem }\end{array}$ & Manual & \\
\hline 1 & $44 \mathrm{a} 99 \mathrm{e} 2 \mathrm{ec} 4 \mathrm{a} 81$ & 1 & 45,000 & 45,000 & Sesuai \\
\hline 2 & $471 \mathrm{~b} 1 \mathrm{e} 2 \mathrm{ec} 4 \mathrm{a} 80$ & 2 & 53,000 & 53,000 & Sesuai \\
\hline 3 & $4528 \mathrm{de} 2 \mathrm{ec} 4 \mathrm{a} 80$ & 3 & 36,000 & 36,000 & Sesuai \\
\hline 4 & $44 \mathrm{fbbe} 2 \mathrm{ec} 4 \mathrm{a} 80$ & 6 & 84,000 & 84,000 & Sesuai \\
\hline 5 & $43 \mathrm{ac} 4 \mathrm{e} 2 \mathrm{ec} 4 \mathrm{a} 81$ & 4 & 62,500 & 62,500 & Sesuai \\
\hline
\end{tabular}

Hasil pengujian pada Tabel 4.4 dapat dilihat bahwa dari lima kali pengujian perhitungan tagihan atau bill oleh sistem, kesemuanya sesuai dengan perhitungan manual. Dapat disimpulkan bahwa tingkat keberhasilan perhitungan tagihan atau bill oleh sistem sebesar $100 \%$.

\section{KESIMPULAN}

Berdasarkan hasil pengujian dan implememntasi sistem pemesanan makanan dan minuman pada restoran menggunakan teknologi NFC berbasis android dapat disimpulkan:

1. Sistem dapat membaca NFC tag dan mengetahui nomor meja melalui smart phone dengan tingkat keberhasilan $100 \%$,

2. Jarak maksimal pembacaan NFC tag oleh smart phone adalah $2.5 \mathrm{~cm}$.

3. Rata-rata waktu tunggu pelanggan direspon oleh sistem adalah sebesar 1.16 detik.

4. Sistem mampu melakukan perhitungan billing untuk pembayaran dengan tingkat keakuratan $100 \%$. 


\section{DAFTAR PUSTAKA}

[1] Supriatna, Dedi. 2012. Studi Mengenai Aspek pada system RFID www.cert.or.id/ budi/courses/security/20062007/Report-Dedi-Supriatna.pdf.

[2] Soekresno. 2013. Management Food and Beverage, service hotel. Jakarta: PT Gramedia Pustaka Umum, hlm. 17. (Diakses pada Mei 2017)

[3] Fahmi, Hidayatullah. 2013. Rancang Bangun Sistem Keamanan Keluar Masuk Parkir dengan Kartu Cerdas Mifare dan Teknologi Near Field Communication (NFC) Studi Kasus Parkir Jurusan Teknik Informatika. Surabaya: Institut Teknologi Sepuluh November.

[4] Krisnanda, Made. 2011. Penggunaan Teknologi Near Field Communication Pada Telepon Seluler Untuk Micro Paymentdan Loyalty Management. Konsultan Teknologi Informasi, Jurnal Informatika: Semarang.

[5] Zainudin, Ahmad. 2013. Pengenalan Android. Surabaya: Politeknik Elektronika Negri Surabaya.

[6] Prima HP, Ignatius. 2014. Penggunaan Raspberry pi Sebagai Web Server pada Rumah untuk Sistem Pengendali Lampu Jarak Jauh dan Pemantau Suhu.Salatiga.

[7] M. Reza, Faruq. 2013. Penggunaan Router untuk Membatasi Akses Situs Jejaring Sosial.Semarang: Universitas Diponegoro. 